Article

\title{
Optimal Design of an Air-to-Air Heat Exchanger with Cross-Corrugated Triangular Ducts by Using a Particle Swarm Optimization Algorithm
}

\author{
Caihang Liang ${ }^{1, *}$, Xiaoman Tong ${ }^{1}$, Tengyue Lei ${ }^{1}$, Zhenxing $\mathrm{Li}^{2}$ and Guoshan $\mathrm{Wu}^{3}$ \\ 1 School of Mechano-Electronic Engineering, Guilin University of Electronic Technology, Guilin 541004, China; \\ xiaoman_tong@yahoo.com (X.T.); tyl2308@yahoo.com (T.L.) \\ 2 Department of Environmental Engineering, Shan Xi University, Taiyuan 030006, China; lzx422@sxu.edu.cn \\ 3 Department of Energy and Built Environment, Guilin University of Aerospace Technology, \\ Guilin 541004, China; wuguoshan@guat.edu.cn \\ * Correspondence: lianghang@guet.edu.cn; Tel.: +86-773-229-2386
}

Academic Editor: Takahiko Miyazaki

Received: 22 March 2017; Accepted: 17 May 2017; Published: 26 May 2017

\begin{abstract}
Air-to-air heat exchangers with cross-corrugated triangular ducts are widely used in various industrial fields to recover waste heat. The geometric parameters of the heat exchangers greatly affect the performance and total annual cost of these systems. In this study, the effectiveness-number of transfer units ( $\varepsilon$-NTU) method was utilized to develop the thermal mathematical model, which was verified by comparing it with previous research. The configuration parameters of the heat exchanger were optimized in this study. The particle swarm optimization (PSO) algorithm was applied using both single and multi-objective algorithm. The colburn factor ( $j$ factor), friction factor ( $f$ factor), and comprehensive thermal hydraulic performance index ( $J F$ factor) were considered as objective functions to be optimized using a single objective and multi-objective algorithm. Then, the entropy generation rate and total annual cost were optimized by using a multi-objective PSO algorithm. In addition, to identify the influential geometric parameters, a global sensitivity analysis was performed. The sensitivity analysis showed that the apex angle $\theta$, channel height $H$, and heat exchanger height $L_{\mathrm{h}}$ influenced the performance and annual total cost of these systems.
\end{abstract}

Keywords: cross-corrugated triangular ducts; air-to-air heat exchanger; particle swarm analysis (PSO); global sensitivity analysis

\section{Introduction}

Air-to-air heat exchangers with cross-corrugated triangular ducts are widely used in many applications, such as electronic cooling, aerospace, air conditioning and refrigeration, petroleum refineries, automobiles, and chemical industries. Figure 1 shows the schematic of the air-to-air heat exchanger with cross-corrugated triangular ducts, where the two unmixed cross flows exchange heat through the corrugated plate. Flat plates are corrugated to form a series of parallel equilateral triangular ducts. Sheets of the same corrugated plates are then stacked together to form a $90^{\circ}$ orientation angle, which guarantees the same flow pattern for the fluid on both side. Compared with air-to-air heat exchangers with other channel ducts, the air-to-air heat exchangers with cross-corrugated triangular ducts have some advantages like higher heat exchange capacity, higher mechanical strength and more compact size [1].

In recent years, the heat exchangers with cross-corrugate triangular ducts have attracted attention owing to their advantages. Many researchers have investigated the characteristics of heat transfer and flow of the cross-corrugated heat exchangers to enhance the heat transfer and decrease the pressure 
loss [2-7]. Some researchers studied the effect of geometric parameters on the thermohydraulic characteristics of the cross-corrugated heat exchangers. Forck et al. [8] experimentally investigated the effect of the corrugation inclination angle on the thermohydraulic performance of plates from $0^{\circ}$ to $90^{\circ}$. The results showed that the heat transfer and pressure drop increased with an increase of corrugation inclination angle. Zimmerer et al. [9] experimentally investigated the effect of the geometric parameters like the inclination angle, the wavelength, the amplitude and the shape of corrugation on thermohydraulic performance of the corrugated heat exchangers. Their results showed that the geometries were of significant influence on the heat transfer and pressure drop. Kumar et al. [10] conducted a series of experiments to study the effect of chevron angle on heat transfer performance in plate heat exchangers using $\mathrm{ZnO} /$ water nanofluid. Zhao et al. [11] numerically investigated the inclination angle on the performance of the corrugated heat exchanger. Liu and Niu [12] studied the effect of Apex angle and aspect ratio on heat transfer, pressure drop and thermohydraulic performance of periodic cross-corrugated channels using Computational Fluid Dynamics (CFD). They showed that Apex angle strongly influenced the heat transfer and pressure drop in triangular cross-section corrugated channels. The aspect ratio had a relatively greater impact on flow friction loss, compared to its effect on the heat transfer. These experimental and numerical studies identified that the geometric parameters have a significant effect on the thermohydraulic characteristics of the exchanger.

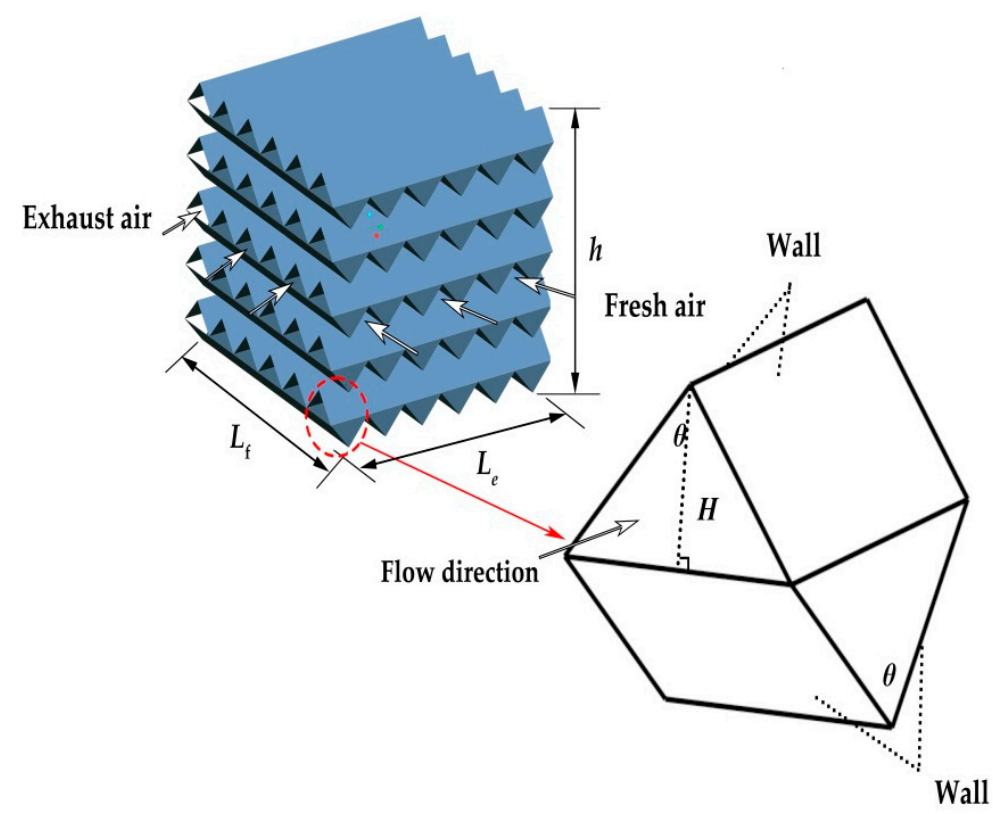

Figure 1. Schematic of an air-to-air heat exchanger core with cross-corrugated triangular ducts.

Geometric optimization is one effective way of enhancing the heat transfer and decreasing the pressure drop. The entropy generation minimization (EGM), proposed by Bejan [13], is a very useful technology to optimize the thermal process, thermal system and thermal equipment. The EGM is based on the theory that a thermodynamically optimized system is the least irreversible, or minimum entropy generation in the system. Doba and Ogulata [14] used the EGM to optimize the cross-flow heat exchanger. They found that the minimum entropy generation number depended on flow path length, dimensionless mass velocity, and dimensionless heat transfer. Farzaneh-Gord et al. [15] minimized the entropy generation number of tube-tube heat exchanger to develop analytical expressions for optimal value of tube diameter, Dean number and Reynolds number. Rashidi et al. [16] studied thermal-hydraulic and entropy generation for turbulent flow inside a corrugated channel. Ghanbarpour and Khodabandeh [17] investigated the entropy generation of cylindrical heat pipe using nanofluid. The results showed that entropy generation in heat pipe decreased when nanofluids were using working fluids instead of base fluid. 
The design of air-to-air heat exchanger involves many geometric and operating variables. These geometric and operating variables are a part of the search for an exchanger geometry that meets the heat duty requirement and a given set of design constraints. The conventional optimization techniques become very cumbersome and laborious for optimizing the design parameter of the heat exchanger. In recent decades, many researchers have applied intelligent algorithms for optimization of air-to-air heat exchangers. Wang et al. [18] used a multi-objective genetic algorithm to obtain the optimal values of the pitch and height of undulated plate and the height of the corrugated plate by using the Pareto optimal strategy. In their studies, the heat transfer capability and pumping power were the objective functions. Mehrgoo and Amidpour [19] investigated the optimum design of the heat recovery steam generator using the genetic algorithm method under the fixed total volume condition. The total entropy generation was considered as the objective function. Peng and Ling [20] demonstrated the successful application of the genetic algorithm combined with back propagation neural networks for the optimal design of plate-fin heat exchangers. Several investigators used other intelligent algorithms like the biogeography-based optimization algorithm [21], adaptive simulated annealing algorithm [22], bees algorithm [23], cuckoo search algorithm [24] and the Jaya algorithm [25], to optimize the heat exchangers.

The particle swarm optimization (PSO) algorithm is a relative recent heuristic search method. It is based on the idea of collaborative behavior and swarming in biological populations. PSO is a population-based search approach, and depends on information sharing among their population members to enhance their process using a combination of deterministic and probabilistic rule. Recently, some researchers have used the PSO for heat exchanger and thermal system optimization. Weter and Weight [26] used the PSO to solve optimization problems for building design and control. Rao and Patel $[27,28]$ applied the PSO to optimize the cross-flow plate-fin heat exchanger and shell-and-tube heat exchangers. The results demonstrated successful application of PSO techniques for the thermodynamic optimization of heat exchangers. Yousefi et al. [29] investigated the optimal design of a compact heat exchanger using PSO. Numerical results indicated that the PSO generated the optimum configuration with higher accuracy and a higher success rate. Dastmalchi et al. [30] employed PSO to determine the optimal micro-finned geometric which maximizes the thermal efficiency of micro-finned double pipe heat exchangers.

From the references mentioned above, there are few studies on optimizing the design of air-to-air heat exchangers with cross-corrugated triangular ducts using the PSO. In the present work, the mathematical model of air-to-air heat exchangers with cross-corrugated triangular ducts is developed. The entropy generation rate $\dot{S}_{\text {gen }}$, and total annual cost $C_{\text {total }}$ are considered as the objection functions by single objective and multi-objective optimization with specified mass flow rate under a given space. To guide the design of air-to-air heat exchangers with cross-corrugated triangular ducts, the $j$ factor, $f$ factor, and $J F$ factor are defined as objective functions. The six heat exchanger design parameters: fresh air channel length $L_{\mathrm{f}}$, exhaust air length $L_{\mathrm{e}}$, channel height $H$, apex angle $\theta$, heat exchanger height $L_{\mathrm{h}}$, and plate thickness $\delta_{\text {plate }}$ are considered as the optimization parameters. In addition, to determine the influential input parameters over defined parameter space, global sensitivity analysis (GSA) should be performed.

\section{Mathematical Model}

In this section, the following assumptions were made: (1) no heat exchange between the outer surface and the surrounding environment occurred; (2) air was assumed to be the working fluid, and the thermal physical properties were assumed to be constant and ideal gases [24]; (3) the configuration parameters of the flow channels on the fresh air side and the exhaust air side were assumed to be identical, except for the total channel length; (4) The numbers of plate plies on each side were assumed to be identical. These assumptions were made for each calculation in this study. 


\subsection{Entropy Generation Analysis}

Based on the EGM technique, the $\dot{S}_{\text {gen }}$ (entropy generation rate of the air-to-air exchanger) is expressed in terms of the temperature and pressure using the ideal gas model on both sides $\left(\left(R_{\mathrm{a}}, c_{\mathrm{p}}\right)_{\mathrm{f}}\right.$ and $\left.\left(R_{\mathrm{a}}, c_{\mathrm{p}}\right)_{\mathrm{e}}\right)$, as shown in Equation (1) [31]:

$$
\dot{S}_{\mathrm{gen}}=\left(\dot{m} c_{\mathrm{p}}\right)_{\mathrm{f}}\left[\ln \frac{T_{\mathrm{fo}}}{T_{\mathrm{fi}}}-\left(\frac{R_{\mathrm{a}}}{c_{\mathrm{p}}}\right)_{\mathrm{f}} \ln \frac{P_{\mathrm{fo}}}{P_{\mathrm{fi}}}\right]+\left(\dot{m} c_{\mathrm{p}}\right)_{\mathrm{e}}\left[\ln \frac{T_{\mathrm{eo}}}{T_{\mathrm{ei}}}-\left(\frac{R_{\mathrm{a}}}{c_{\mathrm{p}}}\right)_{\mathrm{e}} \ln \frac{P_{\mathrm{eo}}}{P_{\mathrm{ei}}}\right]
$$

where $R_{\mathrm{a}}$ is ideal gas constant, $c_{\mathrm{p}}$ is specific heat at constant pressure, $\dot{m}$ is mass flow rate. $T$ and $P$ are temperature and pressure, respectively. Subscripts $i$, and o mean inlet and outlet, respectively. Subscripts f, e, mean fresh air, exhaust air, respectively. Equation (1) indicates that $\dot{S}_{\text {gen }}$ is generated by two behaviors of the heat exchanger: heat transfer and fluid flow.

\subsubsection{Heat Transfer}

The heat transfer behavior of the core is summarized by the classical $\varepsilon$-NTU method. The parameter $\varepsilon$ is the effectiveness of the heat exchanger. The effectiveness $\varepsilon$ of the cross-flow heat exchanger with both fluids unmixed is shown in Equation (2) [32].

$$
\varepsilon=1-\exp \left\{\frac{N T U^{0.22}}{c_{\mathrm{R}}}\left[\exp \left(-c_{\mathrm{R}} N T U^{0.78}\right)-1\right]\right\}
$$

where $c_{R}$ and the number of transfer units $(N T U)$ are defined as follows:

$$
\begin{gathered}
c_{\mathrm{R}}=\frac{\min \left[\left(\dot{m} c_{\mathrm{p}}\right)_{\mathrm{f}^{\prime}}\left(\dot{m} c_{\mathrm{p}}\right)_{\mathrm{e}}\right]}{\max \left[\left(\dot{m} c_{\mathrm{p}}\right)_{\mathrm{f}^{\prime}}\left(\dot{m} c_{\mathrm{p}}\right)_{\mathrm{e}}\right]} \\
N T U=\frac{K A_{\text {total }}}{c} \\
c=\min \left[\left(\dot{m} c_{\mathrm{p}}\right)_{\mathrm{f}^{\prime}}\left(\dot{m} c_{\mathrm{p}}\right)_{\mathrm{e}}\right]
\end{gathered}
$$

The parameter $A_{\text {total }}$ is the total heat transfer area. It is twice as large as the total area of the corrugated triangular plates in the heat exchanger. The parameter $A$ is the total area of the corrugated triangular plates, which is calculated as follows:

$$
A=A_{\text {cyc }} \cdot \frac{L_{\mathrm{f}}}{2 H \cdot \tan \frac{\theta}{2}} \cdot \frac{L_{\mathrm{e}}}{2 H \cdot \tan \frac{\theta}{2}} \cdot \frac{L_{\mathrm{h}}}{2 H+2 \delta_{\text {plate }}}
$$

The parameter $A_{\text {cyc }}$ is the surface area of a unitary cell of the core, and $L_{\mathrm{f}}, L_{\mathrm{e}}$ and $L_{\mathrm{h}}$ are the fresh air channel length, exhaust air channel length and height of the heat exchanger, respectively. In addition, the $H, \theta$ and $\delta_{\text {plate }}$ are channel height, apex angle and thickness of plate, respectively.

The total heat transfer coefficient $K$ in Equation (4) is expressed in Equation (7):

$$
K=\frac{1}{\frac{1}{h_{\mathrm{f}}}+\frac{\delta_{\text {plate }}}{\lambda_{\text {plate }}}+\frac{1}{h_{\mathrm{e}}}}
$$

where $\lambda_{\text {plate }}$ is thermal conductivity of the plate. The parameters $h_{\mathrm{f}}$ and $h_{\mathrm{e}}$ are convective heat transfer coefficients of the fresh air and exhaust air, respectively. The convective heat transfer coefficient $h$ is defined by Equation (8):

$$
h=\frac{\lambda_{\mathrm{a}} N u}{D_{\mathrm{h}}}
$$


The parameter $N u$ is the Nusselt number. Zhang [33] developed a correlation of the corrugated triangular ducts under uniform heat flux boundary conditions.

$$
N u=0.274 \operatorname{Re}^{0.569} \mathrm{Pr}^{0.333}
$$

The Colburn factor $j$, is a heat transfer performance index of the heat exchanger, which is defined in Equation (10).

$$
j=\frac{N u}{\operatorname{Re} \cdot \operatorname{Pr}^{1 / 3}}
$$

The heat transfer rate is expressed in Equation (11):

$$
Q=\varepsilon c\left(T_{\mathrm{fi}}-T_{\mathrm{ei}}\right)
$$

In addition, the heat balance between the two streams is calculated as follows:

$$
\left\{\begin{array}{l}
Q=\left(\dot{m} c_{\mathrm{p}}\right)_{\mathrm{f}}\left(T_{\mathrm{fi}}-T_{\mathrm{fo}}\right) \\
Q=\left(\dot{m} c_{\mathrm{p}}\right)_{\mathrm{e}}\left(T_{\mathrm{eo}}-T_{\mathrm{ei}}\right)
\end{array}\right.
$$

Then, the outlet temperatures of two sides are expressed as follows:

$$
\begin{gathered}
T_{\mathrm{fo}}=T_{\mathrm{fi}}-\frac{\varepsilon c\left(T_{\mathrm{fi}}-T_{\mathrm{ei}}\right)}{\left(\dot{m} c_{\mathrm{p}}\right)_{\mathrm{f}}} \\
T_{\mathrm{eo}}=T_{\mathrm{ei}}+\frac{\varepsilon c\left(T_{\mathrm{fi}}-T_{\mathrm{ei}}\right)}{\left(\dot{m} c_{\mathrm{p}}\right)_{\mathrm{e}}}
\end{gathered}
$$

\subsubsection{Fluid Flow}

The outlet pressures $\left(P_{\mathrm{fo}}\right.$ and $\left.P_{\mathrm{eo}}\right)$ refer to the analysis of the pressure drops experienced by the two streams. The Reynolds number $R e$ is defined in Equation (14).

$$
\operatorname{Re}=\frac{\rho_{\mathrm{a}} v_{\mathrm{m}} D_{\mathrm{h}}}{\mu}
$$

The parameter $v_{\mathrm{m}}$ is the area-weighted mean velocity in the inlet $(\mathrm{m} / \mathrm{s}) . \mu$ is dynamic viscosity (Pa s). The parameter $D_{\mathrm{h}}$ is the hydraulic diameter of the channel and is defined in Equation (15) [1].

$$
D_{\mathrm{h}}=\frac{4 V_{\mathrm{cyc}}}{A_{\mathrm{cyc}}}
$$

The parameters $V_{\text {cyc }}$ and $A_{\text {cyc }}$ are the volume and surface area of the channel, respectively.

$$
\begin{aligned}
A_{\mathrm{cyc}} & =4 \cdot\left(2 H \cdot \tan \frac{\theta}{2}\right) \cdot \frac{H}{\cos \frac{\theta}{2}} \\
V_{\mathrm{cyc}} & =2 \cdot\left(H^{2} \cdot \frac{\theta}{2}\right) \cdot\left(2 H \cdot \tan \frac{\theta}{2}\right)
\end{aligned}
$$

The correlation friction factor $f$ is used by the correlations of Zhang [33], presented as follows:

$$
f=6.536 R e^{-0.421}
$$

Pressure drop of channels is associated with the air density, area-weighted mean velocity, channel length $L$ and hydraulic diameter, thus the outlet pressures $\left(P_{\mathrm{fo}}\right.$ and $\left.P_{\mathrm{eo}}\right)$ of the heat exchanger are expressed as follows: 


$$
\begin{gathered}
P_{\mathrm{fo}}=P_{\mathrm{fi}}-\frac{\frac{1}{2} f_{\mathrm{f}} \rho_{\mathrm{a}} v_{\mathrm{m}}^{2} L_{\mathrm{f}}}{D_{\mathrm{h}}} \\
P_{\mathrm{eo}}=P_{\mathrm{ei}}-\frac{\frac{1}{2} f_{\mathrm{e}} \rho_{\mathrm{a}} v_{\mathrm{m}}^{2} L_{\mathrm{e}}}{D_{\mathrm{h}}}
\end{gathered}
$$

In addition, the comprehensive thermal hydraulic performance index JF is defined in Equation (21) [34].

$$
J F=\frac{j}{f^{1 / 3}}
$$

\subsection{Total Annual Cost}

For the optimal design of heat exchanger, the total annual cost is an important factor that needs to be considered. The total annual cost of the air-to-air heat exchanger is composed of the investment cost and the operating cost of fans. The total annual cost of the exchanger is as follows:

$$
C_{\text {total }}=C_{\mathrm{inv}}+C_{\mathrm{ope}}
$$

where $C_{\text {inv }}$ and $C_{\text {ope }}$ are the investment cost and the operating cost, respectively. The investment cost is calculated by [24]:

$$
C_{\mathrm{inv}}=\phi \cdot C_{\mathrm{A}} \cdot A^{\sigma}
$$

where the parameter $C_{\mathrm{A}}$ is the cost for per unit area. $\phi$, the annual cost coefficient, is calculated as follows:

$$
\phi=\frac{\alpha}{1-(1+\alpha)^{-y}}
$$

the parameters $\alpha$ and $y$ represent the inflation rate and the depreciation time, respectively.

The operating cost calculation is shown in the following formula [24]:

$$
C_{\text {ope }}=\frac{\kappa \cdot \tau \cdot \Delta P_{\mathrm{f}} \cdot \frac{\dot{Q}_{\mathrm{f}}}{3600}}{\eta}+\frac{\kappa \cdot \tau \cdot \Delta P_{\mathrm{e}} \cdot \frac{\dot{Q}_{\mathrm{e}}}{3600}}{\eta}
$$

The parameters $\kappa, \tau$, and $\eta$ are the electric cost, operation time per year, and fan efficiency. The cost coefficients in this study are listed in Table 1.

Table 1. Cost coefficients of the air-to-air heat exchanger with cross-corrugated triangular ducts.

\begin{tabular}{cc}
\hline Economic Parameters & Values \\
\hline Depreciation time, $y$ (year) & 10 \\
Inflation rate, $\alpha$ & 0.1 \\
Cost per unit area, $C_{\mathrm{A}}\left(\$ \mathrm{~m}^{-2}\right)$ & 20 \\
Exponent of non-liner of increase factor, $\sigma$ & 0.6 \\
Electric price, $\kappa\left(\$ \mathrm{~kW}^{-1} \mathrm{~h}^{-1}\right)$ & 0.15 \\
Yearly running time, $\tau(\mathrm{h}$ year & $-1)$ \\
Fan efficiency, $\eta$ & 5000 \\
\hline
\end{tabular}

\section{Modeling Validation}

In this section, the mathematical model is validated by comparing it with the literature data [2]. The validated results are listed in Table 2 . The exterior dimensions are $462 \times 185 \times 185 \mathrm{~mm}$, and the internal character dimensions are a channel height of $L_{\mathrm{h}}=2.8 \mathrm{~mm}$, an apex angle of $\theta=\pi / 2$, and a plate thickness of $\delta_{\text {plate }}=100 \mu \mathrm{m}$. The operating parameters are air flow rates of $\dot{Q}_{\mathrm{f}}\left(\dot{Q}_{\mathrm{e}}\right)=150 \mathrm{~m}^{3} / \mathrm{h}$ and 
the thermal conductivity of the triangular corrugated plate, $\lambda_{\text {plate }}=0.127 \mathrm{~W} /(\mathrm{m} \mathrm{K})$. The fresh air temperature and exhaust air temperature are $308 \mathrm{~K}$ and $300 \mathrm{~K}$, respectively.

Table 2. Comparison and validation of model parameters.

\begin{tabular}{cccc}
\hline \multirow{2}{*}{ Properties } & \multicolumn{3}{c}{ Values } \\
\cline { 2 - 4 } & Literature Study [2] & Present Study & Error \\
\hline$R e$ & 532 & 499 & $6.20 \%$ \\
$f$ & 0.503 & 0.478 & $5.16 \%$ \\
$\Delta P(\mathrm{~Pa})$ & 53 & 52.6 & $4.97 \%$ \\
$N u$ & 10.44 & 9.318 & $10.75 \%$ \\
$h_{\mathrm{f}}, h_{\mathrm{e}}\left(\mathrm{W} \mathrm{m} \mathrm{m}^{-2} \mathrm{~K}^{-1}\right)$ & 63.2 & 56.4 & $10.7 \%$ \\
$\varepsilon_{\mathrm{s}}$ & 0.86 & 0.80 & $6.97 \%$ \\
\hline
\end{tabular}

From Table 2, the simulation results agreed well with the calculation results from [2].

\section{Optimization Methods}

\subsection{Particle Swarm Optimization}

Particle swarm optimization (PSO), developed by Kennedy and Eberhart [35], is an evolutionary computation technique for solving global optimization problems. The 'swarm intelligence' has been widely applied to solve multivariable optimal design problems and shows good properties: it is easier to understand, easier to realize, faster in search velocity and quite suitable for real value processing.

This computational technique was derived from the study of predatory behavior. The synchrony of the animal's behavior is maintained by optimal distances between the individual members and their neighbors. Thus, velocity is important for adjusting the optimal distances between the individual members. For foraging, the individuals update their velocities by two factors: their previous experience and the experience of the other members. The two factors are expressed by the self-cognition term and social cognition term in the velocity equation, respectively. In this artificial intelligence algorithm, a particle represents a potential solution, and each particle corresponds to a fitness value determined by the fitness function. The velocity of particles determines the direction and distance of the particle movement, and the speed of the particle is dynamically adjusted according to the experience of the movement of all of the particles. Then, the optimization of the individuals in the solution space can be obtained. The characteristics of the particles are represented by three indexes: position, velocity, and fitness.

The updates of the particles are accomplished using the following equations [35]:

$$
\begin{aligned}
& v_{\xi d, I t e r+1}=\omega v_{\xi d, I t e r}+b_{1} r_{1}\left(\text { pbest }_{\xi d, I t e r}-X_{\xi d, I t e r}\right)+b_{2} r_{2}\left(g b e s t_{\xi d, I t e r}-X_{\xi d, I t e r}\right) \\
& Z_{\xi d, I t e r+1}=Z_{\xi d, I t e r}+v_{\xi d, I t e r+1}
\end{aligned}
$$

The velocity, position, personal best, and group best of particle $\xi$ are respectively expressed as the $D$-dimensional vectors, $v_{\xi}=\left(v_{\xi 1}, v_{\xi 2}, \ldots, v_{\xi D}\right)^{T}, Z_{\xi}=\left(X_{\xi 1}, X_{\xi 2}, \ldots, X_{\xi D}\right)^{T}$, pbest $_{\xi}=\left(\text { pbest }_{\xi 1}, \text { pbest }_{\xi 2}, \ldots, \text { pbest }_{\tilde{\zeta}}\right)^{T}$, and gbest $_{\xi}=\left(\text { gbest }_{\tilde{\zeta} 1}, \text { gbest }_{\xi 2}, \ldots, \text { gbest }_{\xi D}\right)^{T}$. The parameter Iter represents the current number of iterations, $d=1,2, \ldots, D$ and $\xi=1,2, \ldots, n$. The parameters $b_{1}$ and $b_{2}$ denote the cognitive and social parameters, respectively, which represent the weighting of the stochastic acceleration terms that pull each particle toward 'pbest' and 'gbest' positions. Low values of the acceleration factor allow particles to roam far from target regions before being tugged back, while high values result in abrupt movement toward, or passing through target regions. Kennedy and Eberhart suggested that $b_{1}=b_{2}=2$ could be better to trade off the two factors. The parameters $r_{1}$ and $r_{2}$ are the random numbers and they range from 0 to 1 . The parameter $\omega$ represents the inertia weight, and at the beginning of the iteration, a larger inertia weight makes the algorithm maintain 
stronger global search ability. In the latter iteration, a smaller inertia weight creates more accurate local searching. In this study, we use a commonly used empirical formula, and it is expressed in Equation (28) [36]:

$$
\omega=\omega_{\text {start }}-\left(\omega_{\text {start }}-\omega_{\text {end }}\right)\left(\frac{\text { Iter }}{\text { Iter }_{\max }}\right)^{2}
$$

$\omega_{\text {start }}$ is 0.9 and $\omega_{\text {end }}$ is 0.4 . Figure 2 is a flowchart of PSO algorithm. In the present work, PSO algorithm is run by considering the following parameters:

Particle dimension: $D=6$

Number of particles: $n=50$

Maximum number of generations: Iter $_{\max }=200$

Variation of inertial weight: $0.4 \leq \omega \leq 0.9$

Cognitive parameter: $b_{1}=2$

Social parameter: $b_{2}=2$

Maximum velocity: $v_{\max }=5$

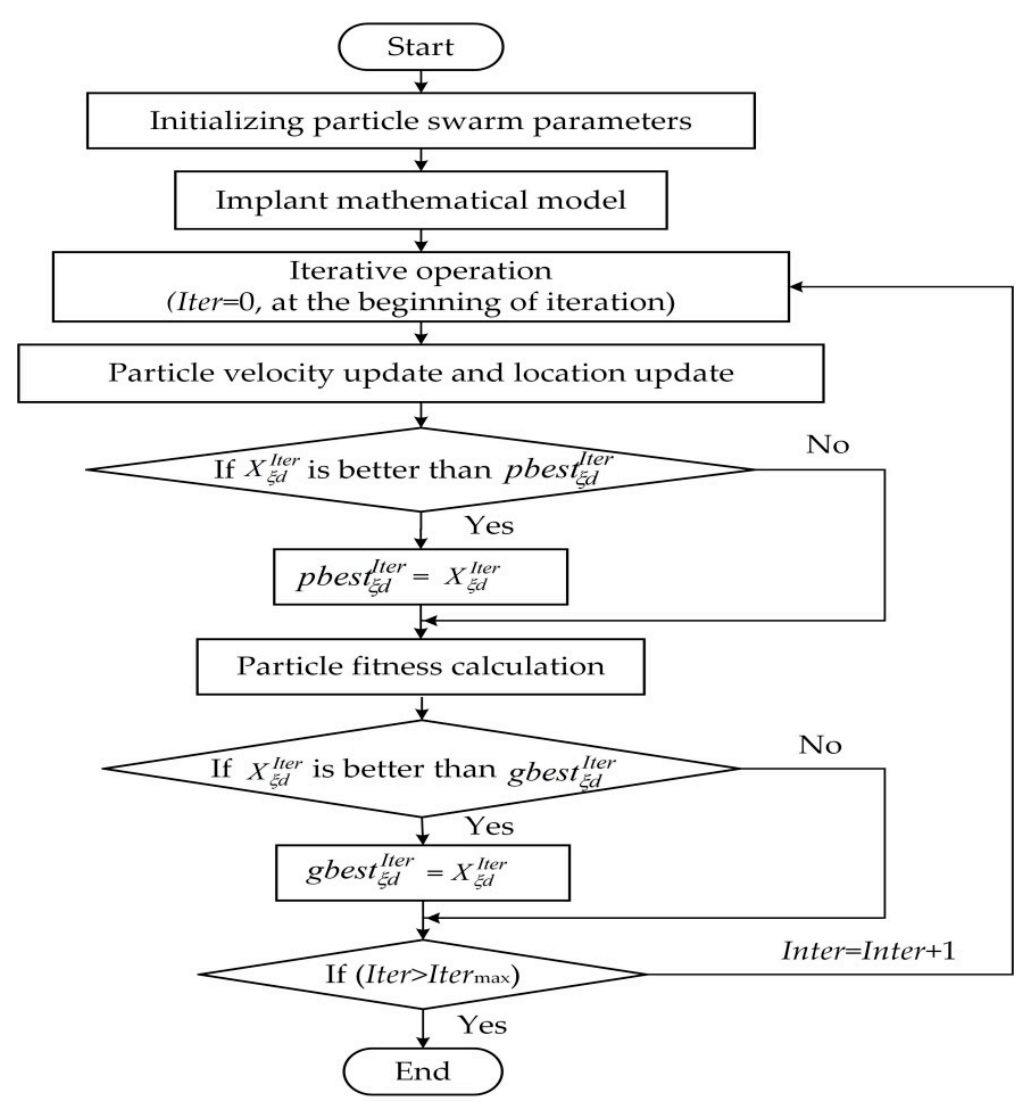

Figure 2. Flowchart of the particle swarm optimization (PSO) algorithm.

The fitness function calculation is conducted by determining the objective function. The particle update is determined by the procedure termination criteria 'if $(\text { Iter }>\text { Iter } \max )^{\prime}$. Then, the best global optimal values are recorded.

\subsection{Objective Functions and Constraints}

In present work, $j$ factor, $f$ factor, $J F$ factor, entropy generation rate $\dot{S}_{\text {gen }}$ and total annual cost $C_{\text {total }}$ are optimization goals and presented as follows: 


$$
\begin{gathered}
j=F_{1}\left(L_{\mathrm{f}}, L_{\mathrm{e}}, \theta, H, \delta_{\text {plate }}, L_{\mathrm{h}}\right)=F_{1}\left(x_{1}, x_{2}, x_{3}, x_{4}, x_{5}, x_{6}\right)=F_{1}(X) \\
f=F_{2}\left(L_{\mathrm{f}}, L_{\mathrm{e}}, \theta, H, \delta_{\text {plate }}, L_{\mathrm{h}}\right)=F_{2}\left(x_{1}, x_{2}, x_{3}, x_{4}, x_{5}, x_{6}\right)=F_{2}(X) \\
J F=F_{3}\left(L_{\mathrm{f}}, L_{\mathrm{e}}, \theta H, \delta_{\text {plate }}, L_{\mathrm{h}}\right)=F_{3}\left(x_{1}, x_{2}, x_{3}, x_{4}, x_{5}, x_{6}\right)=F_{3}(X) \\
\dot{S}_{\text {gen }}=F_{4}\left(L_{\mathrm{f}}, L_{\mathrm{e}}, \theta, H, \delta_{\text {plate }}, L_{\mathrm{h}}\right)=F_{4}\left(x_{1}, x_{2}, x_{3}, x_{4}, x_{5}, x_{6}\right)=F_{4}(X) \\
C_{\text {total }}=F_{5}\left(L_{\mathrm{f}}, L_{\mathrm{e}}, \theta, H, \delta_{\text {plate }}, L_{\mathrm{h}}\right)=F_{5}\left(x_{1}, x_{2}, x_{3}, x_{4}, x_{5}, x_{6}\right)=F_{5}(X)
\end{gathered}
$$

The optimization objective in present work is to obtain the $j_{\max }, f_{\min }$, and $J F_{\max }$, minimum $\dot{S}_{\text {gen }}$, and minimum $C_{\text {total. }}$. The values $x_{1}, x_{2}, x_{3}, x_{4}, x_{5}$ and $x_{6}$ in Equation (29) to Equation (33) are the optimized variables in the objective functions, and correspond to $L_{\mathrm{f}}, L_{\mathrm{e}}, \theta, H, \delta_{\text {plate }}$ and $L_{\mathrm{h}}$.

The design variables and the constraint conditions are listed in Table 3.

Table 3. Range of variables.

\begin{tabular}{cc}
\hline Variables & Constraints \\
\hline$L_{\mathrm{f}}$ & $0.15-0.5 \mathrm{~m}$ \\
$L_{\mathrm{e}}$ & $0.15-0.5 \mathrm{~m}$ \\
$\theta$ & $\pi / 10-9 \pi / 10 \mathrm{rad}$ \\
$H$ & $0.002-0.01 \mathrm{~m}$ \\
$\delta_{\text {plate }}$ & $0.001-0.002 \mathrm{~m}$ \\
$L_{\mathrm{h}}$ & $0.1-0.7 \mathrm{~m}$ \\
\hline
\end{tabular}

In present study, to take in to account the effect of constraint violation during the optimization process, an arbitrarily large value (known as penalty function) is also added. The fitness function is defined as Equation (34) [37]:

$$
\text { fitness }=\Phi(X)=\left\{\begin{array}{l}
F_{t}(X) \\
F_{t}(X)+(-1)^{\Omega} M \sum_{u=1}^{12}\left[g_{u}(X)\right]^{2} x \text { is in the feasible region }
\end{array}\right.
$$

where the penalty coefficient $M=500, g_{u}(X)$ is penalty function. $\Omega$ equal to 0 or 1 depend on the objective function $F_{t}$. In this work, when the objective function aim at achieving $f_{\min }$, minimum $\dot{S}_{\text {gen }}$ and minimum $C_{\text {total }}, \Omega=0$, and $\Omega=1$ when $F_{t}$ is to obtain $j_{\max }$ and $J F_{\max }$.

\section{Sensitivity Analysis}

A variance-based technique is used to test the sensitivity of the parameters [38]. The model can be represented by:

$$
Y=F_{t}\left(x_{1}, x_{2}, \ldots, x_{6}\right)
$$

The optimized variables $x_{1}, x_{2}, \ldots, x_{6}$ are analyzed. $F_{t}$ stands for the objective function $F_{1}, F_{2}, F_{3}$, $F_{4}$ and $F_{5}$ in Section 4.2. The parameter $Y$ is the model output.

The total variance of $\Psi(Y)$ is expressed as follows [39]:

$$
\Psi(Y)=\sum_{p=1}^{6} \Psi_{p}+\sum_{1 \leq p<q \leq 6} \Psi_{p q}+\ldots+\Psi_{1,2, \ldots, 6}
$$

The parameter $\Psi_{p}$ in Equation (36) is an index measuring the main effect of the parameter $x_{p}$, which is expressed in Equation (37):

$$
\Psi_{p}=\Psi\left[E\left(Y \mid x_{p}\right)\right]
$$


Equation (37) determines the total sensitivity index for the $p$ th parameter and is the sum of all effects involving the parameter $x_{p}$. The parameter $S_{\mathrm{T} p}$ considers the interactions between the $p$ th parameter and the other parameters. The total sensitivity index is denoted by the symbol $S_{\mathrm{T} p}$, which is defined in Equation (38).

$$
S_{\mathrm{T} p}=1-\frac{\Psi_{-}}{\Psi(Y)}
$$

The parameter $\Psi_{-}$is the sum of all of the variance terms that do not include the index $p$.

The sensitivity index is computed using a Monte Carlo method [40]. The principle is to randomly generate samples of parameters within their permissible ranges and to estimate $\Psi(Y), \Psi_{p}$ and $\Psi_{-} p$ as follows:

(1) Choose a base sample dimension $N$.

(2) Generate two random input sample matrices $\boldsymbol{M}_{\mathbf{1}}$ and $\boldsymbol{M}_{\mathbf{2}}$ with the dimensions of $N \times 6$.

$M_{\mathbf{1}}=\left[\begin{array}{cccccc}x_{11} & x_{12} & \ldots & x_{1 i} & \ldots & x_{16} \\ x_{21} & x_{22} & \ldots & x_{2 i} & \ldots & x_{26} \\ \vdots & \vdots & \ldots & \vdots & \ldots & \vdots \\ x_{N 1} & x_{N 2} & \cdots & x_{N i} & \cdots & x_{N 6}\end{array}\right] \boldsymbol{M}_{\mathbf{2}}=\left[\begin{array}{cccccc}x_{11}^{\prime} & x_{12}^{\prime} & \ldots & x_{1 i}^{\prime} & \ldots & x_{16}^{\prime} \\ x_{21}^{\prime} & x_{22}^{\prime} & \ldots & x_{2 i}^{\prime} & \ldots & x_{26}^{\prime} \\ \vdots & \vdots & \ldots & \vdots & \ldots & \vdots \\ x_{N 1}^{\prime} & x_{N 2}^{\prime} & \cdots & x_{N i}^{\prime} & \cdots & x_{N 6}^{\prime}\end{array}\right]$

(3) Define a matrix $N_{p}$ formed from all of the $M_{2}$ columns, except the $p_{t h}$ column, which is taken from matrix $M_{1}$. The matrix $N_{\mathrm{T} p}$ is complementary to $N_{p}$.

$\boldsymbol{N}_{p}=\left[\begin{array}{cccccc}x_{11}^{\prime} & x_{12}^{\prime} & \cdots & x_{1 p} & \ldots & x_{16}^{\prime} \\ x_{21}^{\prime} & x_{22}^{\prime} & \cdots & x_{2 p} & \cdots & x_{26}^{\prime} \\ \vdots & \vdots & & \vdots & \ldots & \vdots \\ x_{N 1}^{\prime} & x_{N 2}^{\prime} & \cdots & x_{N p} & \cdots & x_{N 6}^{\prime}\end{array}\right] N_{\mathrm{T} p}=\left[\begin{array}{cccccc}x_{11} & x_{12} & \ldots & x_{1 p}^{\prime} & \cdots & x_{16} \\ x_{21} & x_{22} & \ldots & x_{2 p}^{\prime} & \ldots & x_{26} \\ \vdots & \vdots & & \vdots & & \vdots \\ x_{N 1} & x_{N 2} & \cdots & x_{N p}^{\prime} & \cdots & x_{N 6}\end{array}\right]$

(4) Calculate the model output, such as the objective function value for all of the input values in the sample matrices $M_{1}$, by obtaining three column vectors of the model outputs with dimensions $N \times 1$, expressed as:

$$
Y=\Theta\left(M_{1}\right) \ldots Y_{\mathrm{T}}^{\prime}=\Theta\left(\boldsymbol{N}_{\mathrm{T} p}\right)
$$

(5) Compute the sensitivity indices based on the scalar products of the above defined vectors of the model outputs:

$$
\Theta_{0}=\frac{1}{N} \sum_{q=1}^{\mathrm{N}} Y^{(q)}
$$

The parameter $\Theta_{0}$ is the mean value of $Y$.

The total variance is calculated using Equation (41) to Equation (43).

$$
\begin{gathered}
\Psi=\frac{1}{N} \sum_{q=1}^{N}\left(Y^{(q)}\right)^{2}-\Theta_{0}^{2} \\
\Psi_{p}=\frac{1}{N} \sum_{q=1}^{N} Y^{(q)} Y^{\prime(q)}-\Theta_{0}^{2} \\
\Psi_{-} p=\frac{1}{N} \sum_{q=1}^{N} Y^{(q)} Y_{T}^{\prime(q)}-\Theta_{0}^{2}
\end{gathered}
$$

\section{Results and Discussion}

\subsection{Thermal Hydraulic Performance Optimization}

The fresh air channel length $L_{\mathrm{f}}$, exhaust air channel length $L_{\mathrm{e}}$, apex angle $\theta$, channel height $H$, plate thickness $\delta_{\text {plate }}$, and height $L_{\mathrm{h}}$ of the heat exchanger are the optimized parameters. The $j$ factor, 
$f$ factor, and $J F$ factor are the objective functions optimized using PSO with single-objective and multi-objective optimization. The physical parameters are listed in Table 4.

Table 4. Physical parameters held constant during the optimal design of the heat exchanger.

\begin{tabular}{cccc}
\hline Physical Parameters & Values & Physical Parameters & Values \\
\hline$c_{\mathrm{pf}}$ & $1.005 \mathrm{~kJ} \mathrm{~kg}^{-1} \mathrm{~K}^{-1}$ & $\dot{Q}_{\mathrm{f}}$ & $100 \mathrm{~m}^{3} \mathrm{~h}^{-1}$ \\
$c_{\mathrm{pe}}$ & $1.005 \mathrm{~kJ} \mathrm{~kg}^{-1} \mathrm{~K}^{-1}$ & $\dot{Q}_{\mathrm{e}}$ & $100 \mathrm{~m}^{3} \mathrm{~h}^{-1}$ \\
$P r_{\mathrm{f}}$ & 0.701 & $\mu_{\mathrm{f}}$ & $1.86 \times 10^{-5} \mathrm{~Pa} \mathrm{~s}$ \\
$P r_{\mathrm{e}}$ & 0.701 & $\mu_{\mathrm{e}}$ & $1.86 \times 10^{-5} \mathrm{~Pa} \mathrm{~s}^{-3}$ \\
$P_{\mathrm{fi}}$ & $1.014 \times 10^{5} \mathrm{~Pa}$ & $\rho_{\mathrm{a}}$ & $1.165 \mathrm{Kg} \mathrm{m}^{-3}$ \\
$P_{\mathrm{ei}}$ & $1.014 \times 10^{5} \mathrm{~Pa}$ & $\lambda_{\mathrm{a}}$ & $0.0263 \times 10^{-3} \mathrm{KW} \mathrm{m}^{-1} \mathrm{~K}^{-1}$ \\
$T_{\mathrm{fi}}$ & $308 \mathrm{~K}$ & $\lambda_{\text {plate }}$ & $2.4 \times 10^{-4} \mathrm{KW} \mathrm{m}^{-1} \mathrm{~K}^{-1}$ \\
$T_{\mathrm{ei}}$ & $300 \mathrm{~K}$ & $R_{\mathrm{a}}$ & $0.287 \mathrm{~kJ} \mathrm{~kg}^{-1} \mathrm{~K}^{-1}$ \\
\hline
\end{tabular}

\subsubsection{Single Objective Optimization}

The $j$ factor is an index of thermal performance of the heat exchanger. The $f$ factor is directly related to the pressure drop in the fresh air channels and exhaust air channels. The JF factor is the heat transfer enhancement comprehensive performance index.

The optimal values of the design parameters with single objective optimization presented in Table 5 are the best optimization results of the 50 operations. The best heat transfer enhancement comprehensive performance is obtained by fresh air channel length $L_{\mathrm{f}}=0.3673 \mathrm{~m}$, exhaust air channel length $L_{\mathrm{e}}=0.3662 \mathrm{~m}$, apex angle $\theta=0.7553 \mathrm{rad}$, channel height $H=0.0032 \mathrm{~m}$, plate thickness $\delta_{\text {plate }}=0.0006 \mathrm{~m}$, and heat exchanger height $L_{\mathrm{h}}=0.5299 \mathrm{~m}$.

Table 5. Optimal results of the thermal hydraulic performance with single objective optimization.

\begin{tabular}{ccccccc}
\hline $\boldsymbol{L}_{\mathbf{f}}(\mathbf{m})$ & $\boldsymbol{L}_{\mathbf{e}}(\mathbf{m})$ & $\boldsymbol{\theta}(\mathbf{r a d})$ & $\boldsymbol{H}(\mathbf{m})$ & $\delta_{\text {plate }}(\mathbf{m})$ & $\boldsymbol{L}_{\mathbf{h}}(\mathbf{m})$ & Objectives \\
\hline 0.3431 & 0.3468 & 0.3322 & 0.0058 & 0.0004 & 0.4086 & $\max j$ factor $3.7463 \times 10^{-2}$ \\
0.1730 & 0.1730 & 2.6452 & 0.0079 & 0.0017 & 0.1299 & $\min f$ factor $1.6932 \times 10^{-1}$ \\
0.3673 & 0.3662 & 0.7553 & 0.0032 & 0.0006 & 0.5299 & $\max J F$ factor $3.8407 \times 10^{-2}$ \\
\hline
\end{tabular}

\subsubsection{Multi-Objective Optimization}

The $j$ factor and $f$ factor are two mutually conflicting indices to unilaterally evaluate the thermal hydraulic performance of a heat exchanger. There is no set of design parameters that simultaneously yields the maximum $j$ factor and the minimum $f$ factor. The PSO algorithm with multi-objective optimization is introduced to search the geometric design parameters to determine the appropriate trade-off of the two objectives. Five sets of representative selected parameters are listed in Table 6. Each of the optimal solutions is a trade-off of the two conflicting objective functions at an appropriate level. These results can be selected by the designer based on the project's limits and the available investment.

Table 6. Selected optimal design parameters of $j$ factor and $f$ factor.

\begin{tabular}{cccccccc}
\hline $\boldsymbol{L}_{\mathbf{f}}(\mathbf{m})$ & $\boldsymbol{L}_{\mathbf{e}}(\mathbf{m})$ & $\boldsymbol{\theta}(\mathbf{r a d})$ & $\boldsymbol{H}(\mathbf{m})$ & $\delta_{\text {plate }}(\mathbf{m})$ & $\boldsymbol{L}_{\mathbf{h}}(\mathbf{m})$ & $j$ Factor & $f$ Factor \\
\hline 0.5000 & 0.4755 & 0.3787 & 0.0021 & 0.0003 & 0.6730 & 0.0772 & 1.8965 \\
0.4933 & 0.4818 & 0.4630 & 0.0024 & 0.0003 & 0.6689 & 0.0665 & 1.6402 \\
0.4832 & 0.4768 & 0.5660 & 0.0025 & 0.0005 & 0.6611 & 0.0577 & 1.4264 \\
0.4536 & 0.4285 & 0.7252 & 0.0033 & 0.0005 & 0.6188 & 0.0440 & 1.0959 \\
0.4140 & 0.4061 & 0.8728 & 0.0044 & 0.0008 & 0.5522 & 0.0331 & 0.8302 \\
\hline
\end{tabular}


6.1.3. Sensitivity Analysis of the Geometric Design Parameters on the Thermal Hydraulic Performance

Figure 3 shows the global sensitivity analysis of design variables. The apex angle $\theta$, channel height $H$, and exchanger height $L_{\mathrm{h}}$ have an influence on the thermal hydraulic performance of the air-to-air heat exchanger with cross-corrugated triangular ducts.

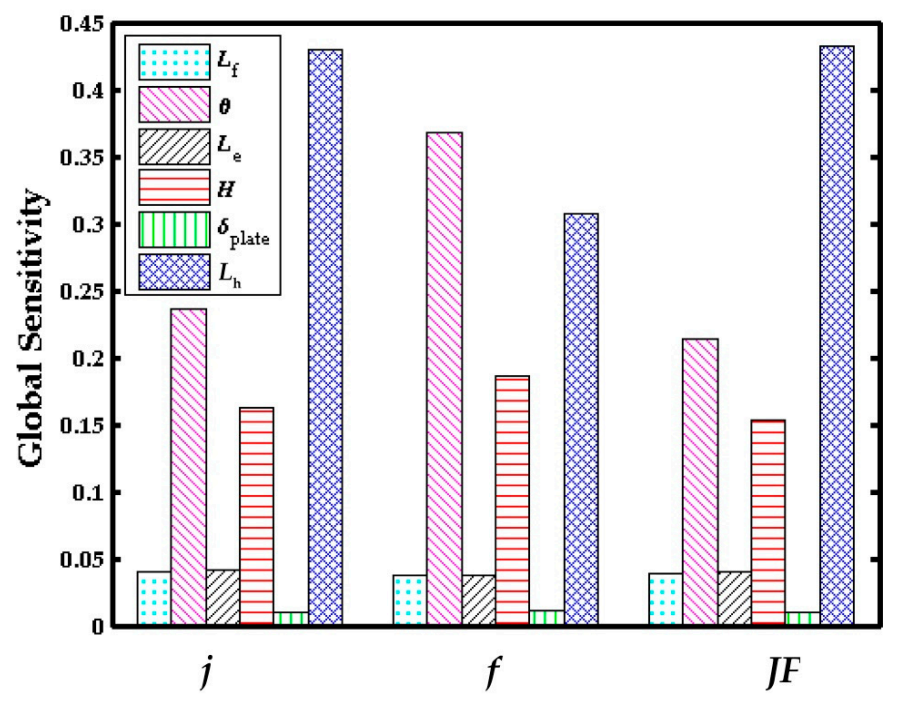

Figure 3. Global sensitivity analysis of the geometric design parameters on the thermodynamic performance.

To understand how these significant design parameters affect the thermal hydraulic performance indexes of the air-to-air heat exchanger, Figure 4 shows how the $j$ factor, $f$ factor, and $J F$ factor vary with the three key design parameters. For the three results, only one input parameter is varied, while the other input parameters remain constant. This indicate that all the indexes, $j$ factor, $f$ factor, and $J F$ factor, decrease with an increasing apex angle $\theta$ and channel height $H$ and increase with an increasing heat exchanger height $L_{\mathrm{h}}$. A bigger apex angle $\theta$ or a larger channel height $H$ results in a bigger cross-sectional area and reduce the heat transfer area when all the other parameters are fixed. These changes create lower heat transfer efficiency and a smaller pressure drop. A larger $L_{\mathrm{h}}$ leads to more air inlets when the volume flow rate and all of the other parameters are fixed, resulting in a reduction of the air flow in per channel. In addition, the heat transfer area is increased. These changes create a larger heat transfer area and a greater pressure loss.

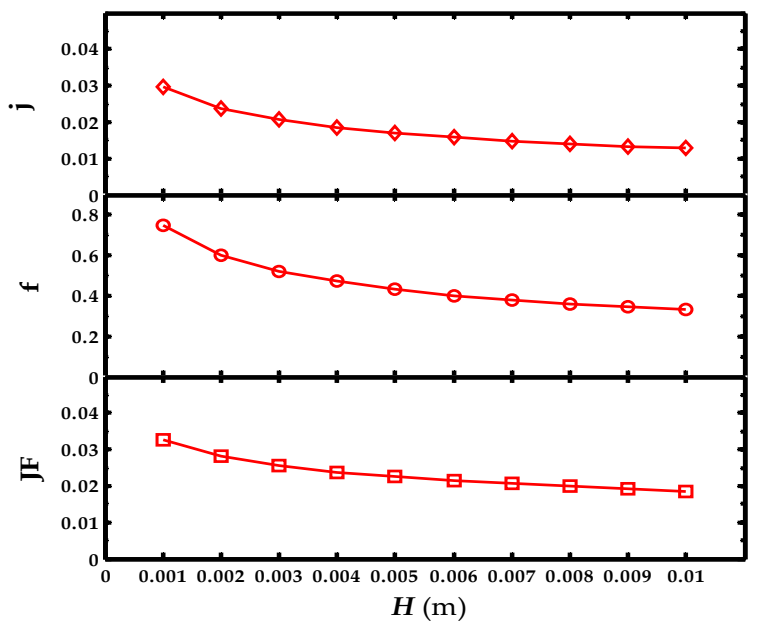

(a)

Figure 4. Cont. 


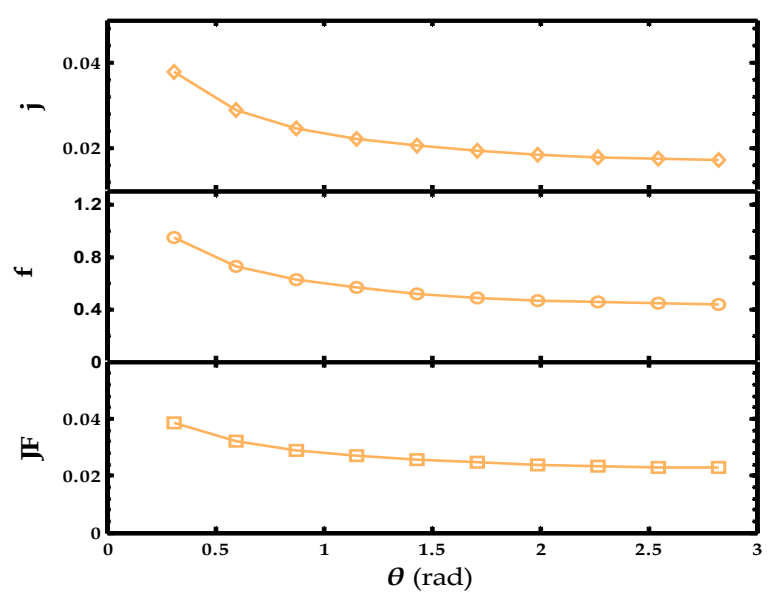

(b)

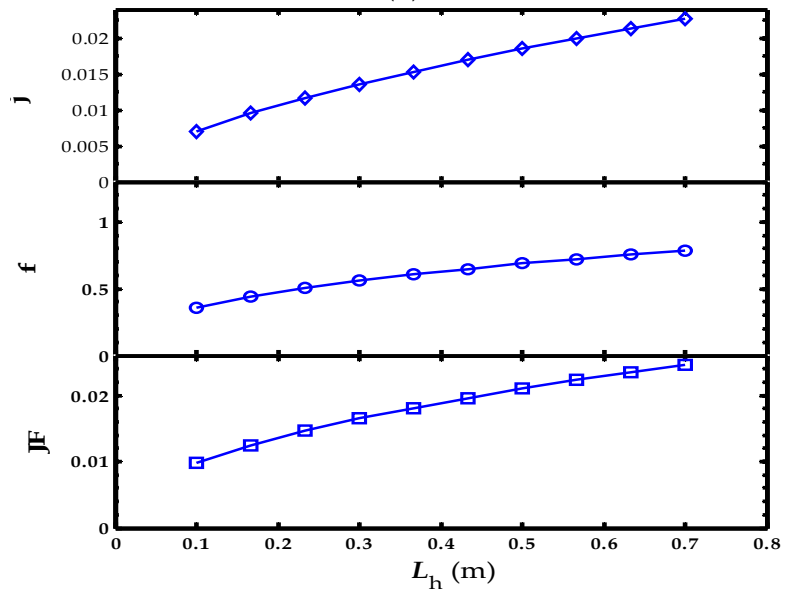

(c)

Figure 4. Graph of the variation of the $j$ factor, $f$ factor, and $J F$ factor with three key variables, (a) channel height; (b) apex angle; and (c) heat exchanger height.

\subsection{Thermal-Economic and Irreversibility Optimization}

The entropy generation analysis is from the point of view of energy balance to evaluate the performance of a heat exchanger. The entropy generation rate and total annual cost are the two objectives optimized by the multi-objective PSO to achieve the design parameters that produce the lowest possible total annual cost and the minimum entropy generation rate.

The fresh air channel length $L_{\mathrm{f}}$, exhaust air channel length $L_{\mathrm{e}}$, apex angle $\theta$, channel height $H$, plate thickness $\delta_{\text {plate, }}$ and height $L_{\mathrm{h}}$ of the heat exchanger are the optimization parameters. The range of these parameters is listed in Table 3 in Section 3, and they are the same as those used in the thermal hydraulic performance optimization. The assumptions are made in Section 2, and the physical parameters held constant in Table 4 remained unchanged during the optimization. In addition, the parameters needed for the total annual cost evaluation are given in Table 1.

The results of the Pareto-optimal points of the entropy generation rate and the total annual cost are shown in Figure 5. The entropy generation rate decreases with an increase in the total annual cost, which means if any one of smaller entropy generation rates replaces another it will always sacrifice quality of total annual cost. Similarly, five of the representative selected optimal design parameters are given in Table 7. A thinner plate thickness, larger channel length, and larger heat exchanger height tend to balance the entropy generation rate and total annual cost.

A global sensitivity analysis results are shown in Figure 6. The bars representing the apex angle, channel height, and heat exchanger height are outstanding in the histogram. 


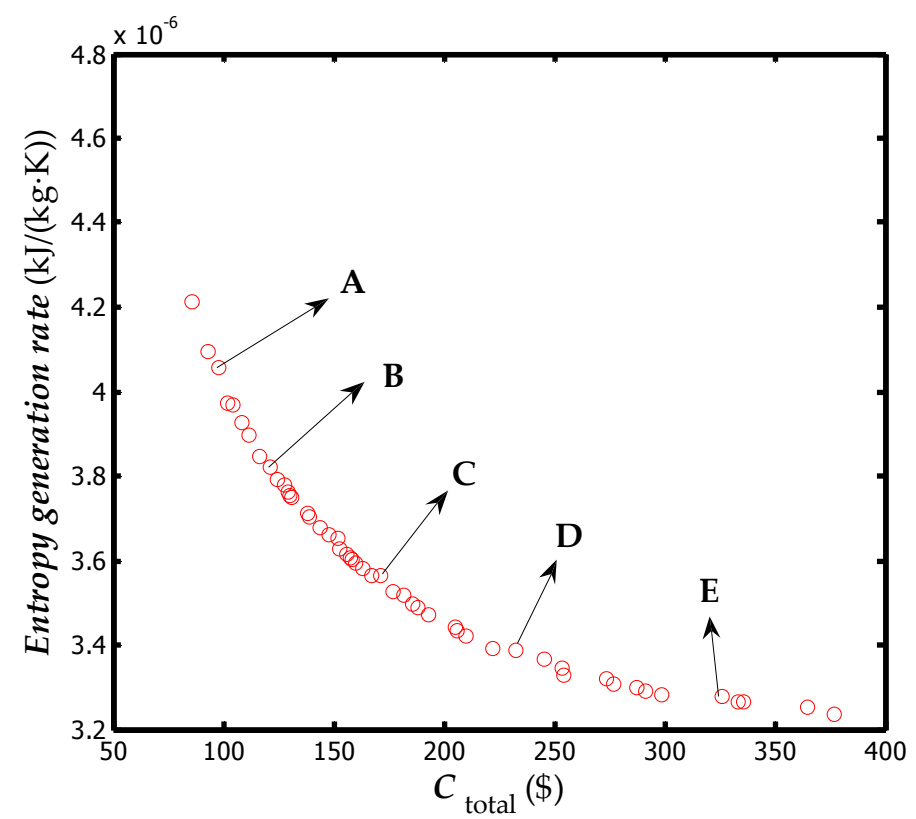

Figure 5. Pareto-optimal points of the entropy generation rate and annual cost.

Table 7. Selected optimal design parameters of the entropy generation rate and annual cost.

\begin{tabular}{ccccccccc}
\hline Points & $\boldsymbol{L}_{\mathbf{f}}(\mathbf{m})$ & $\boldsymbol{L}_{\mathbf{e}}(\mathbf{m})$ & $\boldsymbol{\theta}(\mathbf{r a d})$ & $\boldsymbol{H}(\mathbf{m})$ & $\boldsymbol{\delta}_{\text {plate }}(\mathbf{m})$ & $\boldsymbol{L}_{\mathbf{h}}(\mathbf{m})$ & $\begin{array}{c}\text { Entropy Generation } \\
\left.\text { Rate (kJ Kg } \mathbf{~ K}^{-1}\right)\end{array}$ & $\begin{array}{c}\text { Total Annual } \\
\text { Cost (\$) }\end{array}$ \\
\hline A & 0.4951 & 0.4926 & 2.4079 & 0.0088 & 0.00012 & 0.6979 & $4.096 \times 10^{-6}$ & 93.17 \\
B & 0.4961 & 0.5000 & 1.9156 & 0.0081 & 0.00010 & 0.7000 & $3.822 \times 10^{-6}$ & 121.19 \\
C & 0.4958 & 0.5000 & 1.5615 & 0.0072 & 0.00012 & 0.7000 & $3.562 \times 10^{-6}$ & 171.02 \\
D & 0.5000 & 0.4964 & 1.3027 & 0.0067 & 0.00010 & 0.6946 & $3.389 \times 10^{-6}$ & 232.79 \\
E & 0.5000 & 0.5000 & 1.1138 & 0.0058 & 0.00013 & 0.6953 & $3.264 \times 10^{-6}$ & 336.08 \\
\hline
\end{tabular}

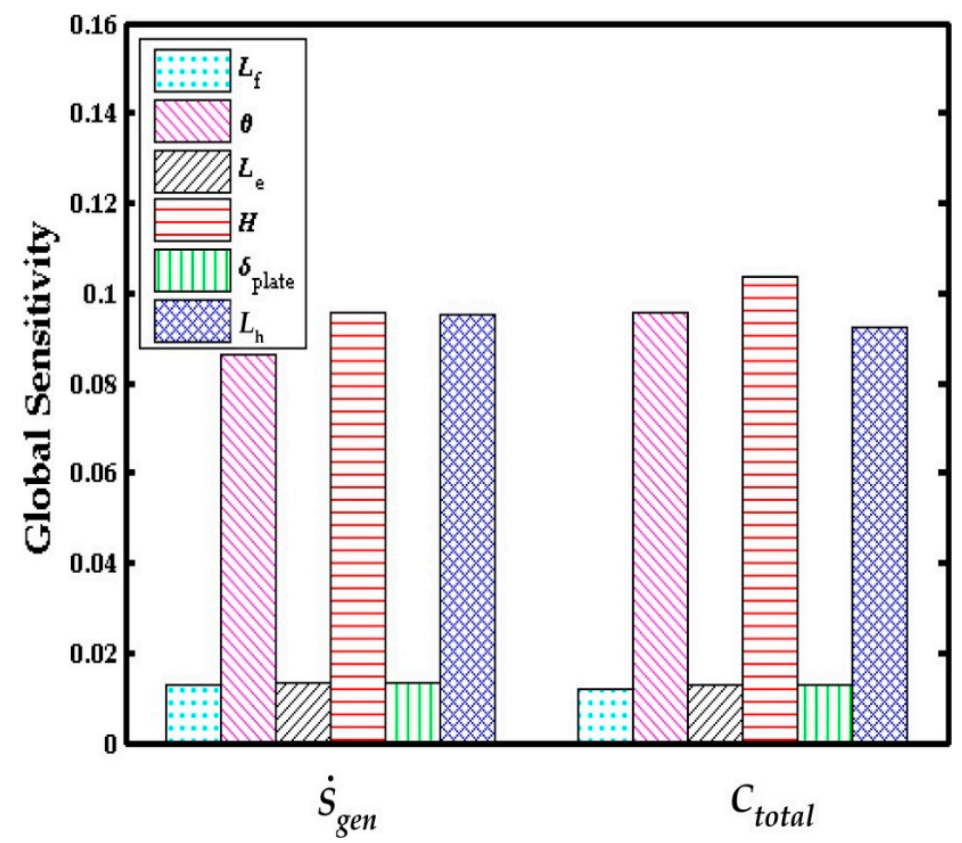

Figure 6. Global sensitivity of cross-corrugated triangular ducts heat exchanger design parameters on entropy and total annual cost. 
To effectively show how these key design parameters affect the entropy generation rate and total annual cost in this design, three charts are made that demonstrate the two objectives changing with the three key parameters. For the three parameters, only one input parameter is varied, while the other input parameters are fixed. Figure $7 \mathrm{a}-\mathrm{c}$ indicates the entropy generation rate and total annual cost change with $H, \theta$, and $L_{\mathrm{h}}$, respectively. The entropy generation rate and total annual cost decrease with the increasing variables and tend to fixed values.

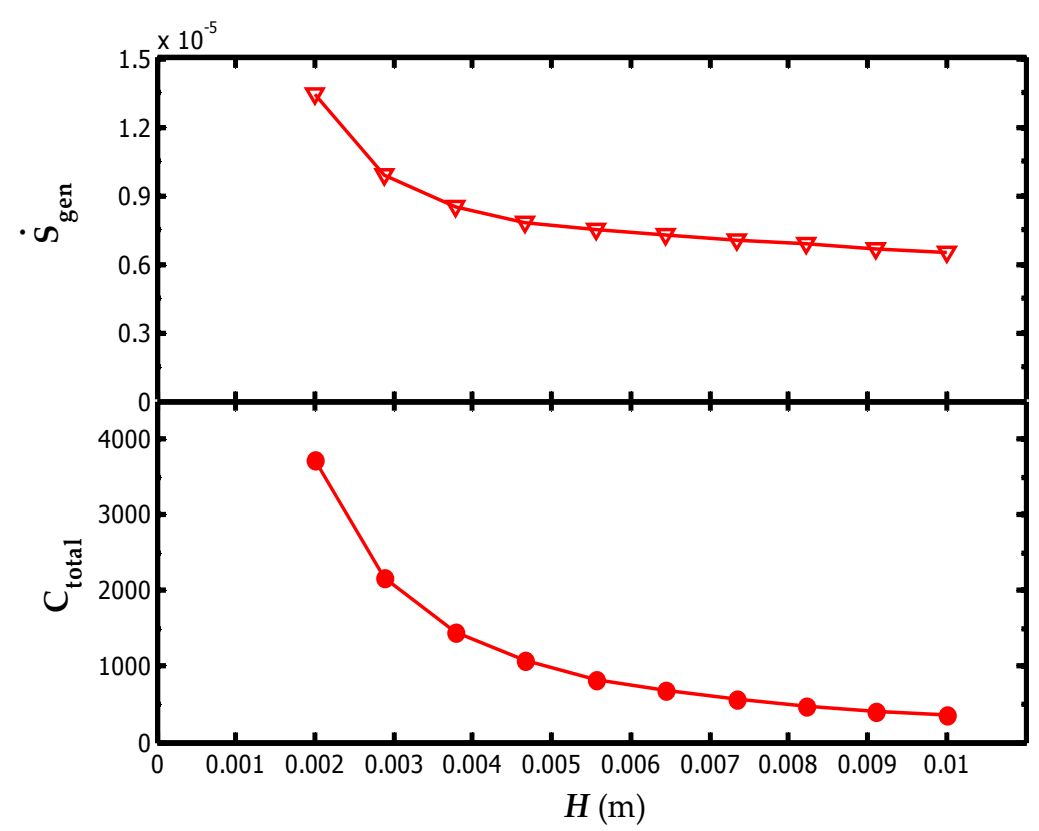

(a)

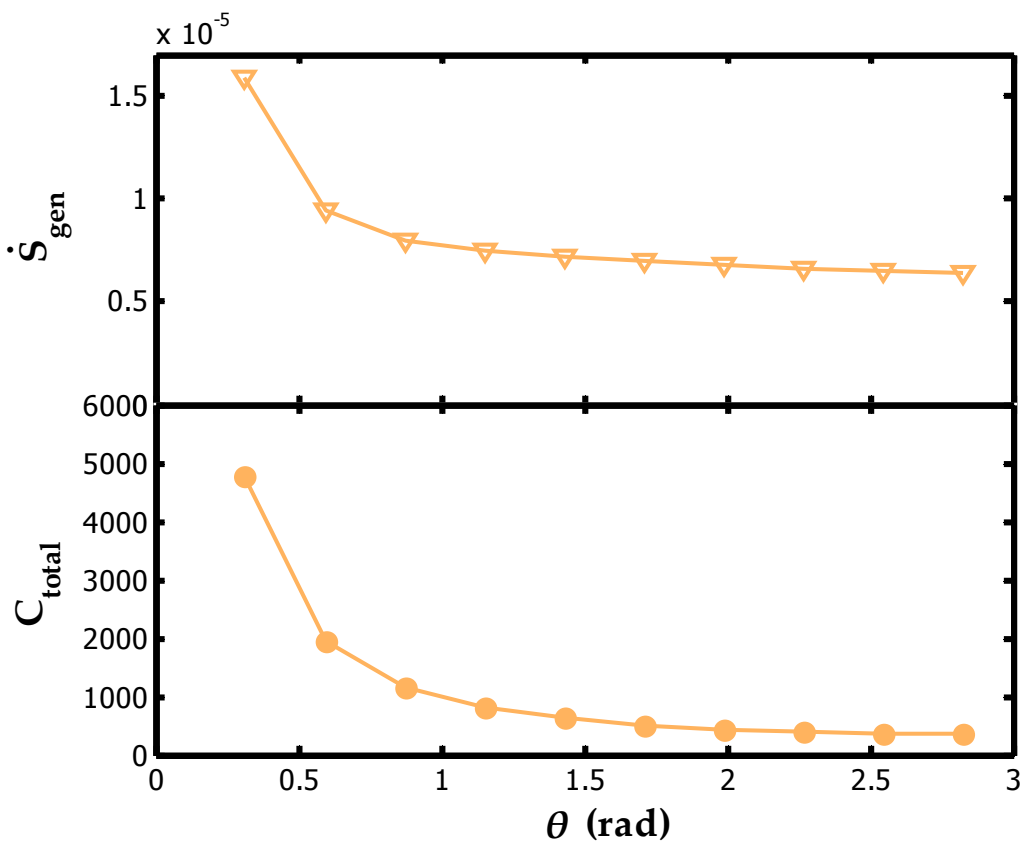

(b)

Figure 7. Cont. 


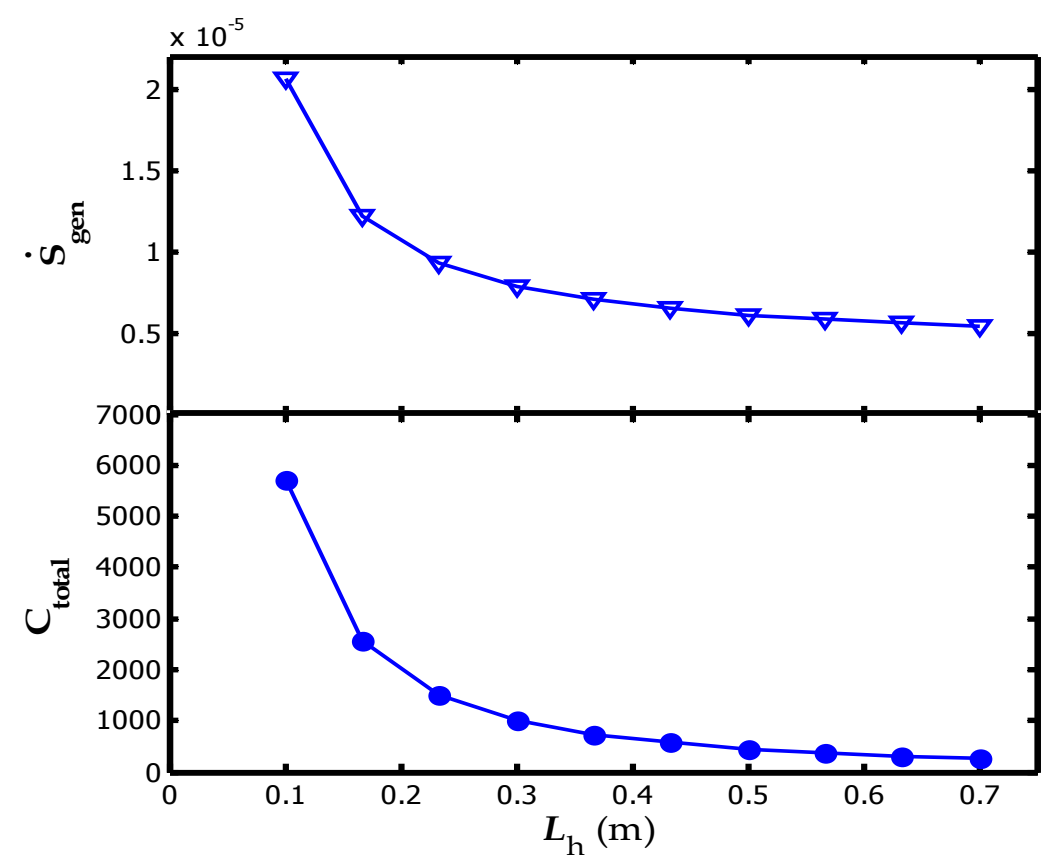

(c)

Figure 7. Variation of the entropy generation rate and total annual cost with three key variables: (a) channel height; (b) apex angle; and (c) heat exchanger height.

\section{Conclusions}

In this study, the thermal hydraulic mathematical model of the air-to-air heat exchanger with cross-corrugated triangular ducts is developed and verified. The PSO is introduced for single and multi-objective optimization of the heat exchanger. The $j$ factor and $f$ factor, and the thermal-economics and irreversibility are two sets of mutually conflicting objectives optimized in this work. Based on this algorithm, the channel length of fresh air $L$, exhaust air channel length $L_{e}$, the apex angle $\theta$ of the isosceles triangle channels, the channel height $H$, the heat exchanger height $L_{\mathrm{h}}$, and the plate thickness $\delta_{\text {plate }}$ are considered as optimization parameters. A sensitivity analysis is carried out for investigating the effect of the design parameters on the multi-objective optimizations. The main conclusions of this study are drawn as follows:

(1) The optimum comprehensive heat transfer enhancement performance is by selecting the best result from 50 operations, when the fresh air channel length $L_{\mathrm{f}}=0.3673 \mathrm{~m}$; the exhaust air channel length $L_{\mathrm{e}}=0.3662 \mathrm{~m}$; the apex angle $\theta=0.7553 \mathrm{rad}$; the channel height is $0.0032 \mathrm{~m}$; the plate thickness $\delta_{\text {plate }}=0.0006 \mathrm{~m}$, and the heat exchanger height $L_{\mathrm{h}}=0.5299 \mathrm{~m}$. In addition, five sets of the selected parameters to balance between $j$ factor and $f$ factor are achieved as selectable to design the heat exchanger with cross-corrugated triangular ducts since each of them is a trade-off on improves heat transfer and reduces friction.

(2) Five sets of optimal design parameters are selected in the thermal-economic and irreversibility multi-objective optimization. A thinner plate thickness, larger channel length, and larger heat exchanger height are propitious to balance the entropy generation rate and total annual cost. These obtained Pareto-optimal points can be selected by the designer based on the project's constraints and the available investment.

(3) In this design, the apex angle $\theta$, the channel height $H$, and the heat exchanger height $L_{\mathrm{h}}$ are the most influential parameters in the global sensitivity analysis for all of the optimization objectives. 
Acknowledgments: This project was jointly supported by The National Natural Science Foundation of China, No. 51566002, Guangxi Colleges and The University Key Lab of Unmanned Aerial Vehicle (UAV), No. WRJ2015KF04, and by the Innovation Project of Guet Graduate Education, Guilin, China, No. 2016YJCX96.

Author Contributions: The paper was a collaborative effort of all authors. Caihang Liang proposed the design ideas, made very useful comments and suggestions, contributed to the English editing and revised the article; Xiaoman Tong performed the simulation and wrote the paper; Tengyue Lei analyzed the data, Zhenxing Li and Guoshan Wu gave some academic advice.

Conflicts of Interest: The authors declare no conflict of interest.

\section{Nomenclature}

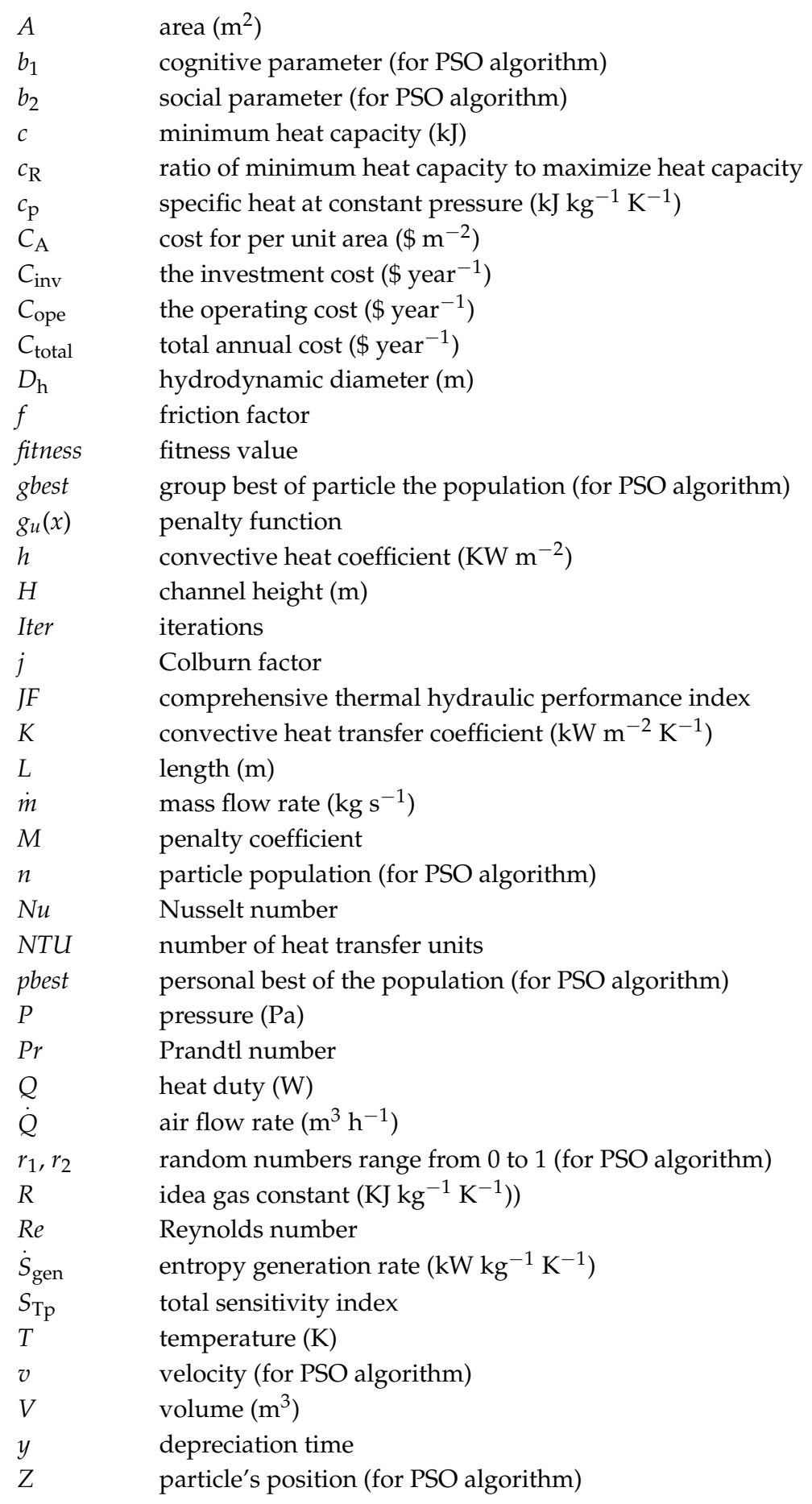




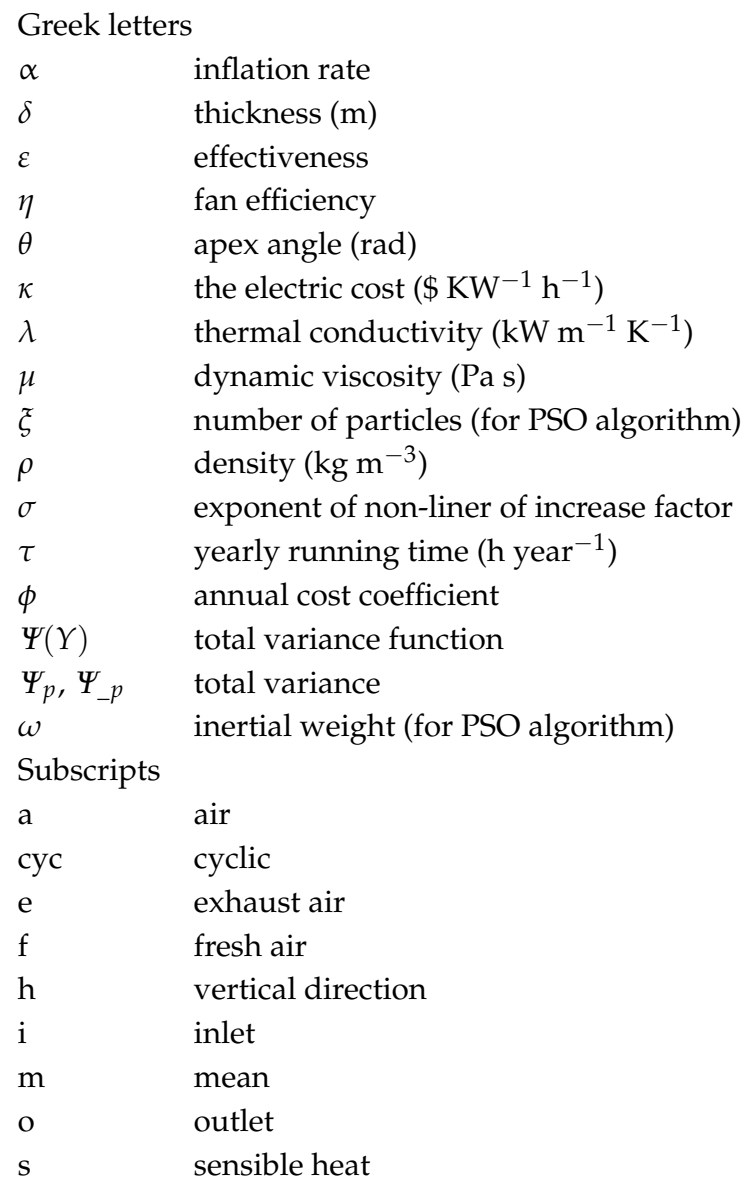

\section{References}

1. Zhang, L.Z. Heat and mass transfer in a total heat exchanger: Cross-corrugated triangular ducts with composite supported liquid membrane. Numer. Heat Transf. A Appl. 2008, 53, 1195-1210. [CrossRef]

2. Li, Z.X.; Zhong, T.S.; Niu, J.L.; Xiao, F.; Zhang, L.Z. Conjugate heat and mass transfer in a total heat exchanger with cross-corrugated triangular ducts and one-step made asymmetric membranes. Int. J. Heat Mass Transf. 2015, 84, 390-400. [CrossRef]

3. Zhang, L.Z.; Chen, Z.Y. Convective heat transfer in cross-corrugated triangular ducts under uniform heat flux boundary conditions. Int. J. Heat Mass Transf. 2011, 54, 597-605. [CrossRef]

4. Lee, J.; Lee, K.-S. Flow characteristics and thermal performance in chevron type plate heat exchangers. Int. J. Heat Mass Transf. 2014, 78, 699-706. [CrossRef]

5. Fernandes, C.S.; Dias, R.P.; Nóbrega, J.M.; Maia, J.M. Friction factors of power-law fluids in chevron-type plate heat exchangers. J. Food Eng. 2008, 89, 441-447. [CrossRef]

6. Tsai, Y.-C.; Liu, F.-B.; Shen, P.-T. Investigations of the pressure drop and flow distribution in a chevron-type plate heat exchanger. Int. Commun. Heat Mass Transf. 2009, 36, 574-578. [CrossRef]

7. Li, Z.; Gao, Y. Numerical study of turbulent flow and heat transfer in cross-corrugated triangular ducts with delta-shaped baffles. Int. J. Heat Mass Transf. 2017, 108, 658-670. [CrossRef]

8. Focke, W.W.; Zachariades, J.; Olivier, I. The effect of the corrugation inclination angle on the thermohydraulic performance of plate heat exchangers. Int. J. Heat Mass Transf. 1985, 28, 1469-1479. [CrossRef]

9. Zimmerer, C.; Gschwind, P.; Gaiser, G.; Kottke, V. Comparison of heat and mass transfer in different heat exchanger geometries with corrugated walls. Exp. Therm. Fluid Sci. 2002, 26, 269-273. [CrossRef]

10. Kumar, V.; Tiwari, A.K.; Ghosh, S.K. Effect of chevron angle on heat transfer performance in plate heat exchanger using zno/water nanofluid. Energy Convers. Manag. 2016, 118, 142-154. [CrossRef]

11. Zhao, Y.; Wu, Y.; Cheng, H.; Zhu, G. Numerical simulation of corrugated inclination angle on the performance of plate heat exchanger. In Proceedings of the 2014 International Conference on Mechatronics, Electronic, Industrial and Control Engineering, Shenyang, China, 15-17 November 2014; Volume 5, pp. 1268-1271. 
12. Liu, X.P.; Niu, J.L. Effects of geometrical parameters on the thermohydraulic characteristics of periodic cross-corrugated channels. Int. J. Heat Mass Transf. 2015, 84, 542-549. [CrossRef]

13. Bejan, A. Second-law analysis in heat transfer and thermal design. In Advances in Heat Transfer; James, P.H., Thomas, F.I., Eds.; Elsevier: New York, NY, USA, 1982; Volume 15, pp. 1-58.

14. Ogulata, R.T.; Doba, F. Experiments and entropy generation minimization analysis of a cross-flow heat exchanger. Int. J. Heat Mass Transf. 1998, 41, 373-381. [CrossRef]

15. Farzaneh-Gord, M.; Ameri, H.; Arabkoohsar, A. Tube-in-tube helical heat exchangers performance optimization by entropy generation minimization approach. Appl. Therm. Eng. 2016, 108, 1279-1287. [CrossRef]

16. Rashidi, S.; Akbarzadeh, M.; Masoodi, R.; Languri, E.M. Thermal-hydraulic and entropy generation analysis for turbulent flow inside a corrugated channel. Int. J. Heat Mass Transf. 2017, 109, 812-823. [CrossRef]

17. Ghanbarpour, M.; Khodabandeh, R. Entropy generation analysis of cylindrical heat pipe using nanofluid. Thermochim. Acta 2015, 610, 37-46. [CrossRef]

18. Wang, L.M.; Deng, L.; Ji, C.L.; Liang, E.K.; Wang, C.X.; Che, D.F. Multi-objective optimization of geometrical parameters of corrugated-undulated heat transfer surfaces. Appl. Energy 2016, 174, 25-36. [CrossRef]

19. Mehrgoo, M.; Amidpour, M. Constructal design and optimization of a dual pressure heat recovery steam generator. Energy 2017, 124, 87-99. [CrossRef]

20. Peng, H.; Ling, X. Optimal design approach for the plate-fin heat exchangers using neural networks cooperated with genetic algorithms. Appl. Therm. Eng. 2008, 28, 642-650. [CrossRef]

21. Hadidi, A.; Nazari, A. Design and economic optimization of shell-and-tube heat exchangers using biogeography-based (bbo) algorithm. Appl. Therm. Eng. 2013, 51, 1263-1272. [CrossRef]

22. Khan, T.A.; Li, W. Optimal design of plate-fin heat exchanger by combining multi-objective algorithms. Int. J. Heat Mass Transf. 2017, 108, 1560-1572. [CrossRef]

23. Zarea, H.; Moradi Kashkooli, F.; Mansuri Mehryan, A.; Saffarian, M.R.; Namvar Beherghani, E. Optimal design of plate-fin heat exchangers by a bees algorithm. Appl. Therm. Eng. 2014, 69, 267-277. [CrossRef]

24. Wang, Z.; Li, Y. Irreversibility analysis for optimization design of plate fin heat exchangers using a multi-objective cuckoo search algorithm. Energy Convers. Manag. 2015, 101, 126-135. [CrossRef]

25. Rao, R.V.; Saroj, A. Constrained economic optimization of shell-and-tube heat exchangers using elitist-jaya algorithm. Energy 2017, 128, 785-800. [CrossRef]

26. Wetter, M.; Wright, J. A comparison of deterministic and probabilistic optimization algorithms for nonsmooth simulation-based optimization. Build. Environ. 2004, 39, 989-999. [CrossRef]

27. Patel, V.K.; Rao, R.V. Design optimization of shell-and-tube heat exchanger using particle swarm optimization technique. Appl. Therm. Eng. 2010, 30, 1417-1425. [CrossRef]

28. Rao, R.V.; Patel, V.K. Thermodynamic optimization of cross flow plate-fin heat exchanger using a particle swarm optimization algorithm. Int. J. Therm. Sci. 2010, 49, 1712-1721. [CrossRef]

29. Yousefi, M.; Enayatifar, R.; Darus, A.N.; Abdullah, A.H. A robust learning based evolutionary approach for thermal-economic optimization of compact heat exchangers. Int. Commun. Heat Mass Transf. 2012, 39, 1605-1615. [CrossRef]

30. Dastmalchi, M.; Sheikhzadeh, G.A.; Arefmanesh, A. Optimization of micro-finned tubes in double pipe heat exchangers using particle swarm algorithm. Appl. Therm. Eng. 2017, 119, 1-9. [CrossRef]

31. Bejan, A. Method of entropy generation minimization, or modeling and optimization based on combined heat transfer and thermodynamics. Rev. Gén. Therm. 1996, 35, 637-646. [CrossRef]

32. Lienhard, J.H. A Heat Transfer Textbook; Phlogiston Press: Cambridge, MA, USA, 2008.

33. Zhang, L.Z. Numerical study of periodically fully developed flow and heat transfer in cross-corrugated triangular channels in transitional flow regime. Numer. Heat Transf. A Appl. 2005, 48, 387-405. [CrossRef]

34. Jamshidi, N.; Farhadi, M.; Sedighi, K.; Ganji, D.D. Optimization of design parameters for nanofluids flowing inside helical coils. Int. Commun. Heat Mass Transf. 2012, 39, 311-317. [CrossRef]

35. Kennedy, J.; Eberhart, R. Particle Swarm Optimization. In Proceedings of the IEEE International Conference on Neural Networks, Perth, Australia, 27 November-1 December 1995; pp. 1942-1948.

36. Ghorbani, B.; Mafi, M.; Shirmohammadi, R.; Hamedi, M.-H.; Amidpour, M. Optimization of operation parameters of refrigeration cycle using particle swarm and nlp techniques. J. Nat. Gas Sci. Eng. 2014, 21, 779-790. [CrossRef]

37. Kaveh, A.; Mahdavi, V.R. A hybrid CBO-PSO algorithm for optimal design of truss structures with dynamic constraints. Appl. Soft Comput. 2015, 34, 260-273. [CrossRef] 
38. Sobol, I.M. Sensitivity analysis for non-linear mathematical models. Math. Model. Comput. Exp. 1993, 1, 407-414.

39. Saltelli, A.; Tarantola, S.; Campolongo, F. Sensitivity analysis as an ingredient of modeling. Stat. Sci. 2000, 15, 377-395.

40. Homma, T.; Saltelli, A. Importance measures in global sensitivity analysis of nonlinear models. Reliab. Eng. Syst. Saf. 1996, 52, 1-17. [CrossRef]

(C) 2017 by the authors. Licensee MDPI, Basel, Switzerland. This article is an open access article distributed under the terms and conditions of the Creative Commons Attribution (CC BY) license (http:/ / creativecommons.org/licenses/by/4.0/). 